\title{
A Commitment to Act: CSHP 2015 and the Blueprint for Pharmacy
}

\author{
Jason Howorko
}

Ceize the opportunity to help shape the future of our profesS sion, or be prepared to live with the fact that when we had the opportunity, we did nothing.

That was the message I took home after hearing a speech by Dr Linda Strand, one of the creators of the pharmaceutical care model, at the Annual National Conference of the Canadian Pharmacists Association. From my perspective, it was a fantastic talk. Personally motivating, in fact. However, I was disappointed to hear what others had to say in the hallway after she spoke. Comments such as "That was crap" and "It will never happen" made me realize that our profession is in a time of crisis: not a crisis because our profession is evolving, but rather a crisis because many pharmacists are completely unaware of or are not yet ready to embrace the changes that are most certainly coming.

Fortunately for many of us who practise in hospitals and related health care settings, change is not new. Over the years, hospital pharmacists have embraced new technology, expanded the scope of practice of pharmacists and technicians, and developed innovative ways to provide care to our patients with limited resources. Now, Canadian pharmacists have 2 new opportunities to shape the development of their profession.

In January 2008, CSHP launched the CSHP 2015 initiative, a progressive, outcomes-based, grassroots initiative to advance hospital pharmacy practice. Baseline data were collected this year, and hospital pharmacy departments and individual hospital pharmacists across the country are now working to meet the CSHP 2015 objectives.

At the same time that CSHP was developing its 2015 initiative, pharmacy regulatory authorities, provincial and national pharmacy associations (including CSHP), faculties of pharmacy, pharmacy students, and pharmacists and pharmacy technicians from hospitals and community practice were creating a united vision for the profession in the Blueprint for Pharmacy: The Vision for Pharmacy (http://www.pharmacists.ca/ content/about_cpha/whats_happening/cpha_in_action/pdf/Blu eprintVision.pdf).
So why should you care about these 2 initiatives?

Many hospital pharmacists perceive that the Blueprint for Pharmacy is only for community pharmacists, and others feel that the Blueprint has no relevance for them because they already practise in an advanced clinical role.

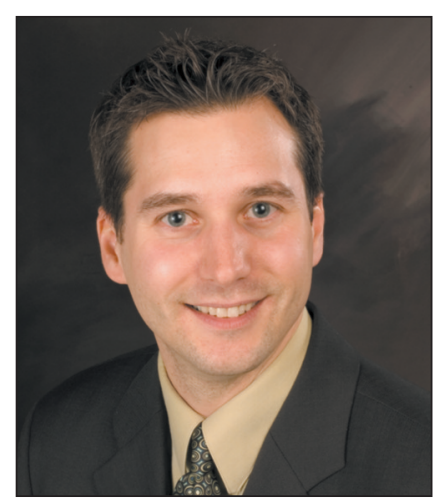
However, many pharmacists face resource and staffing challenges that hinder their advancement, and the Blueprint is designed to help in addressing these issues. In addition, many objectives in the Blueprint are closely aligned with those of the CSHP 2015 initiative. Therefore, CSHP will soon be asking hospital pharmacists and pharmacy departments to endorse these 2 initiatives by signing a "Commitment to Act". Making this formal commitment will demonstrate that you believe in what you are doing as a professional and that you believe all pharmacists should practise in an advanced clinical way.

The vision for practice advancement is here, and now is the time to adopt this vision as your own. This fall, show your support by signing the Commitment to Act on CSHP 2015 and the Blueprint for Pharmacy. Doing so will be your first step in making a difference and promoting the advancement of the profession.

Jason Howorko, BSP, BSC, ACPR, is President and External Liaison for CSHP. 